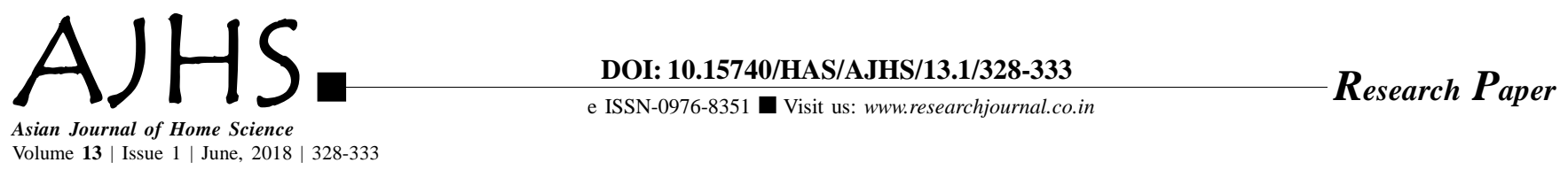

\title{
Evaluation of innovatively designed pouches through Shekhawati motifs
}

Mandeep Kaur and Kanwaljit Brar

Received: 27.01.2018; $\quad$ Revised: 22.04.2018; Accepted: 09.05.2018

See end of the paper for authors' affiliations

Mandeep Kaur

Department of Apparel and

Textile Science, College of Home

Science,Punjab Agricultural

University, Ludhiana (Punjab)

India

Email : mankaur037@gmail.com
DABSTRACT : The present study inspired from the wall paintings of Shekhawat, a semi-desert area in Rajasthan, the investigation entitled "Development of pouches using motifs from Shekhawati paintings" was carried out in Ludhiana city. Out of twenty developed designs of pouches with Shekhawati motifs, ten designs of pouches most preferred by the respondents were prepared. Evaluation of the prepared pouches was done by a sub-sample of thirty respondents. The most preferred pouch on the basis of Shekhawati motifs and designs was $\mathrm{C}_{3}$ with geometrical motif (mean score 8.5). Colour combination of pouch $\mathrm{B}_{4}$ (mean score 6.93), and embellishments of $\mathrm{A}_{1}$ (mean score 6.93) and overall appearance of $\mathrm{C}_{3}$ (mean score 8.9) were most preferred by the respondents. The quoted prices for the prepared pouches $\mathrm{B}_{4} \mathrm{~A}_{2}$ and $\mathrm{E}_{3}$ were found to be adequate with profit margin of $32.04,30.43$ and 28.34 per cent, respectively.

KEY WORDS: Shekhawati motifs, Pouches, Product development, Painting, Profit

- HOW TO CITE THIS PAPER : Kaur, Mandeep and Brar, Kanwaljit (2018). Evaluation of innovatively designed pouches through Shekhawati motifs. Asian J. Home Sci., 13 (1) : 328-333, DOI: 10.15740/HAS/ AJHS/13.1/328-333. Copyright@ 2018: Hind Agri-Horticultural Society. 